\title{
Clinical Efficacy of Amoxicillin versus Cefodoxime Proxetil for the Treatment of Pneumonia
}

\author{
Sajani Islam $^{1}$, Bithi Debnath ${ }^{2}$, Md. Azizul Hoque ${ }^{3}$
}

${ }^{1}$ Junior Consultant (Pediatrics), Upazila Health Complex, Dohar, Dhaka, Bangladesh; ${ }^{2}$ Assistant Professor, Department of Pediatric Neurology, National Institute of Neurosciences and Hospital, Dhaka, Bangladesh; ${ }^{3}$ Professor \&Former Head, Department of Pediatrics, Mymensingh Medical College Hospital, Mymensingh, Bangladesh

[Received: 7March 2019; Accepted: 20 May 2019; Published: 1 June 2019]

\begin{abstract}
Background: Pneumonia is one of the leading cause of death of under 5 children in Bangladesh. WHO recommended Amoxicillin and Co-trimoxazole as first line drugs for the treatment of pneumonia. But emergence of antimicrobial resistance against the common pathogens prompted WHO panel to find out evidence based recommendations for treating pneumonia. Objectives: The purpose of the present study was to compare the effect of oral Amoxicillin and Cefpodoxime proxetil in children with pneumonia.Methodology: This prospective randomized study was conducted in outpatient department of Pediatrics at Mymensingh Medical College Hospital, Mymensingh, Bangladesh from March 2010 to March 2012 for a period of two (02) years. Baseline data were collected from 197 patients, thereafter 85 patients from Amoxicillin group and 89 patients from Cefpodoxime proxetil group completed the trial.Results: Among the enrolled (197) children, majority (53\%) were boys. The baseline clinical characteristics before therapy were not significantly different in both the Amoxicillin and Cefpodoxime proxetil groups. Changes in duration of cough, duration of dyspnea, duration of fast breathing, mean heart rate, temperature and respiratory rate were observed. After treatment with Amoxicillin and Cefpodoxime proxetil similar significant improvement in mean body temperature, respiratory rate and wheeze were observed which were almost similar in both the groups $(\mathrm{p}<0.001)$. While comparing the efficacy, treatment outcome did not differ significantly in both the groups $(p>0.127)$. Chi-square test revealed no statistically significant difference between patients treated with Amoxicillin and those treated with Cefpodoxime proxetil ( $p=0.171$ ). Conclusion: Response to therapy in both Amoxicillin and Cefpodoxime Proxetil groups was nearly similar and the difference was statistically insignificant. [Bangladesh Journal of Infectious Diseases, June 2019;6(1):22-25]
\end{abstract}

Keywords: Pneumonia; Amoxicillin; Cefpodoxime Proxetil; Bangladesh; antibiotic resistant

Correspondence:Dr. Sajani Islam, Junior Consultant (Pediatrics), Upazila Health Complex, Dohar, Dhaka, Bangladesh; Email: sajaniislam@gmail.com;Cell no.: +8801717405779

Conflict of interest: There is no conflict of interest to any of the authors of this article.

Funding agency: The study was not funded by any authority.

Contribution to authors: Islam S, Hoque MAcontributed from protocol writing upto article write up. Debnath B revised and corrected the paper.

How to cite this article: Islam S, Debnath B, Hoque MA. Clinical Efficacy of Amoxicillin versus Cefodoxime Proxetil for the Treatment of Pneumonia. Bangladesh J Infect Dis 2019;6(1):22-25

Copyright: ( 2019 . Islam et al. Published by Bangladesh Journal of Infectious Diseases. This article is published under the Creative Commons CC BY-NC License (https://creativecommons.org/licenses/by-nc/4.0/). This license permits use, distribution and reproduction in any medium, provided the original work is properly cited, and is not used for commercial purposes. 


\section{Introduction}

Acute lower respiratory tract infections especially pneumonia is a global burden. It is the leading killer of children and causes $19 \%$ of total under-five deaths in the world. Pneumonia constitutes $21.0 \%$ deaths occurring in the developing countries, mostly in the South West Asia ${ }^{1}$. In Bangladesh, incidence of pneumonia is very high that accounts up to $18.0 \%$ deaths of this age group ${ }^{2}$. Specific WHO antimicrobial drugs recommendations for the treatment of pneumonia are based on data that Streptococcus pneumonia and Haemophilus influenza are the most common causes of bacteria in these countries. Based on these findings, amoxicillin and cotrimoxazole are recommended for the treatment of pneumonia at primary level of health care facilities ${ }^{3}$.

Although Co-trimoxazole and Amoxicillin are the WHO recommended drugs for pneumonia, high resistance of the pathogens is observed in different studies (Co-trimoxazole $75.0 \%$ and Amoxicillin 32.0 to $35.0 \%)^{4-5}$. Streptococcus pneumoniae and Haemophilus influenzae also exhibits high resistance against macrolides ${ }^{6-10}$. Thus for rising resistance of these two common bacteria against these drugs, it is necessary to find an alternative antibiotic for treatment of pneumonia, such as the third generation cephalosporin.

Cefpodoxime was in fact the most active among oral antibiotic agents tested and covered all major respiratory tract pathogens circulating in the three European countries like Spain, Italy and Austria surveyed. Taking into account its favourable pharmacokinetic parameters and tolerability, Cefpodoxime represents an appropriate choice in the empirical treatment of community acquired respiratory tract infections ${ }^{11-12}$. Considering all these, this study was conducted to observe the clinical efficacy of Cefpodoxime proxetil and Amoxicillin in treatment of pneumonia.

\section{Methodology}

This was an open label randomized controlled trial study conducted in outpatient Department of Paediatrics of Mymensingh Medical College Hospital, Mymensingh, Bangladesh from March 2010 to March 2012 for a period of two years and one month. Patients who met the inclusion criteriawere enrolled in this study. Pneumonia was diagnosed according to WHO criteria. Children having chronic disease, recurrent wheeze, who already started antibiotics and failed to follow up were excluded from the study. Written informed consent was taken from each parent and a randomization scheme was developed after parents chose to have the preferred drug willingly. Then they were divided into two groups of which one group was treated with oral amoxicillin and other group was treated with oral cefpodoxime proxetil.

Amoxicillin was given three times daily $(30 \mathrm{mg} / \mathrm{kg} /$ day) and cefpodoxime proxetil was given twice daily $(10 \mathrm{mg} / \mathrm{kg} /$ day) for five days. Follow up was done on $3^{\text {rd }}$ and $5^{\text {th }}$ day after starting treatment. Patients were declared as cured when the signsymptoms of pneumonia were completely disappeared. The patients who did not cure were needed hospitalization and change in prescribed antibiotics. Data were collected in a preformed questionnaire and statistical analysis was performed by using SPSS version 12 .

\section{Result}

Among 197 enrolled patients 23 respondents could not complete the trial. Finally 85 patients from Amoxicillin group and 89 patients from Cefpodoxime Proxetil group were analyzed.

Table 1: Baseline Characteristics of Study Population

\begin{tabular}{|l|l|l|}
\hline Variables & Group A & Group B \\
\hline Mean age(month \pm SD) & $20.16 \pm 15.79$ & $15.75 \pm 7.87$ \\
\hline Gender & \multicolumn{3}{|l|}{} \\
\hline$\bullet \quad$ Male & $53(54.1 \%)$ & $52(52.5 \%)$ \\
\hline$\bullet \quad$ Female & $45(45.9 \%)$ & $47(47.5 \%)$ \\
\hline Monthly Income & $18(18.4 \%)$ & $17(17.2 \%)$ \\
\hline$\bullet \quad<5000$ & $41(41.8 \%)$ & $44(44.4 \%)$ \\
\hline$\bullet \quad 5000-10000$ & $39(39.8 \%)$ & $38(38.4 \%)$ \\
\hline$\bullet \quad>10000$ & $5(5.1 \%)$ & $7(7.1 \%)$ \\
\hline Person living in one room & $21(21.4 \%)$ & $19(19.2 \%)$ \\
\hline$\quad \leq 2$ & $72(73.5 \%)$ & $73(73.7 \%)$ \\
\hline$\bullet \quad 3$ & $41(41.8 \%)$ & $33(33.3 \%)$ \\
\hline$\bullet \quad \geq 4$ & $57(58.2 \%)$ & $66(66.7 \%)$ \\
\hline Smoking in family & \multicolumn{3}{|l|}{$\mid$\begin{tabular}{l}
$\mid$ \\
\hline$\quad$ Yes
\end{tabular}} \\
\hline No Noup A= Amoxicillin group; Group B=Cefpodoxime Proxetil \\
group
\end{tabular}

Among the enrolled children, the mean age of amoxicillin group was 20.16 months and that for cefpodoxime proxetil was 15.75 months. There were no significant difference regarding the baseline characteristics of patient (Table 1). 
Table 2: Baseline clinical features before therapy

\begin{tabular}{|l|l|l|c|}
\hline Variables & Group A & Group B & $\begin{array}{l}\text { P } \\
\text { value }\end{array}$ \\
\hline $\begin{array}{l}\text { Duration of } \\
\text { cough (Day) } \\
\text { (Mean } \pm \text { SD) }\end{array}$ & $6.89 \pm 3.48$ & $4.59 \pm 0.639$ & 0.57 \\
\hline $\begin{array}{l}\text { Duration of } \\
\text { difficult } \\
\text { breathing (Day) } \\
\text { (Mean } \pm \text { SD) }\end{array}$ & $1.83 \pm 0.38$ & $1.82 \pm 0.388$ & 0.82 \\
\hline $\begin{array}{l}\text { Duration of fast } \\
\text { breathing (Day) } \\
\text { (Mean } \pm \text { SD) }\end{array}$ & $2.11 \pm 0.32$ & $2.01 \pm 0.101$ & 0.70 \\
\hline $\begin{array}{l}\text { Heart rate/min } \\
\text { (Mean } \pm \text { SD) }\end{array}$ & $109.1 \pm 13.81$ & $103.3 \pm 3.69$ & 0.68 \\
\hline
\end{tabular}

\begin{tabular}{|l|l|l|l|}
\hline & & & \\
\hline $\begin{array}{l}\text { Temperature } \\
\left({ }^{0} \mathrm{~F}\right)(\text { Mean } \pm \text { SD) }\end{array}$ & $101.3 \pm 1.96$ & $100.8 \pm 1.67$ & 0.102 \\
\hline $\begin{array}{l}\text { Respiratory } \\
\text { rate/min } \\
(\text { Mean } \pm \text { SD) }\end{array}$ & $47.1 \pm 8.83$ & $49.4 \pm 3.67$ & 0.91 \\
\hline $\begin{array}{l}\text { Chest in drawing } \\
\mathrm{n}(\%)\end{array}$ & $25(25.5 \%)$ & $19(19.2 \%)$ & 1.29 \\
\hline $\begin{array}{l}\text { Added sound, } \\
\mathrm{n}(\%)\end{array}$ & $33(33.7 \%)$ & $41(41.4 \%)$ & 0.912 \\
\hline
\end{tabular}

Group A= Amoxicillin group; Group B= Cefpodoxime Proxetil group

Baseline clinical features before therapy were also statistically insignificant (Table 2).

Table 3: Response to therapy with Amoxicillin $(n=85)$

\begin{tabular}{|l|c|c|c|c|}
\hline Variables & Before Treatment & After Treatment & 95\% CI & P value \\
\hline $\begin{array}{l}\text { Body Temperature } \\
\text { (Mean } \pm \text { SD) }\end{array}$ & $100.47 \pm 1.24$ & $99.35 \pm 1.97$ & 0.781 to 1.463 & $<0.001$ \\
\hline $\begin{array}{l}\text { Respiratory rate } \\
\text { (Mean } \pm \text { SD) }\end{array}$ & $47.39 \pm 9.05$ & $44.22 \pm 9.51$ & 1.637 to 4.692 & $<0.001$ \\
\hline Added sound $\mathrm{n}(\%)$ & $28(32.9)$ & $01(1.18)$ & & $<0.001$ \\
\hline
\end{tabular}

Table 4: Response to therapy with Cefpodoxime Proxetil $(n=89)$

\begin{tabular}{|l|c|c|c|c|}
\hline Variables & Before Treatment & After Treatment & 95\% CI & P value \\
\hline $\begin{array}{l}\text { Body Temperature } \\
(\text { Mean } \pm \text { SD) }\end{array}$ & $99.29 \pm 1.63$ & $98.78 \pm 1.65$ & 0.197 to 0.805 & 0.002 \\
\hline $\begin{array}{l}\text { Respiratory rate } \\
(\text { Mean } \pm \text { SD) }\end{array}$ & $49.08 \pm 3.77$ & $44.809 \pm 7.79$ & 2.946 to 5.616 & $<0.001$ \\
\hline Added sound, $\mathrm{n}(\%)$ & $35(39.3)$ & 00 & & $<0.001$ \\
\hline
\end{tabular}

Table 5: Comparison of response to therapy in both groups

\begin{tabular}{|l|c|c|c|c|}
\hline Variables & Group A & Group B & 95\% CI & P value \\
\hline Body Temperature $($ Mean \pm SD) & $99.35 \pm 1.97$ & $98.78 \pm 1.65$ & -3.17 to 2.02 & 0.44 \\
\hline Respiratory rate $($ Mean \pm SD) & $44.22 \pm 9.51$ & $44.80 \pm 7.79$ & 0.015 to 1.11 & 0.66 \\
\hline Added sound, $\mathrm{n}(\%)$ & $01(1.18)$ & 00 & & 0.127 \\
\hline
\end{tabular}

Group $\mathrm{A}=$ Amoxicillin group; Group $\mathrm{B}=$ Cefpodoxime Proxetil group

Table 6: Comparison of treatment outcome in both groups

\begin{tabular}{|c|c|c|c|}
\hline Variables & Group A & Group B & $\begin{array}{l}\mathbf{P} \\
\text { value }\end{array}$ \\
\hline Cured & $68(80 \%)$ & $77(86.5 \%)$ & \multirow{3}{*}{0.171} \\
\hline Not cured & $17(20 \%)$ & $12(13.5)$ & \\
\hline Total & $85(100.0 \%)$ & $89(100.0 \%)$ & \\
\hline
\end{tabular}

Group $\mathrm{A}=$ Amoxicillin group; Group $\mathrm{B}=$ Cefpodoxime Proxetil group

After treatment with the Amoxicillin (Table-3) and

Cefpodoxime Proxetil (Table 4), significant improvement $(\mathrm{p}<0.001)$ in mean body temperature, respiratory rate and added sound were observed in both groups which were almost similar.

When we compared the response to therapy (Table 5) and treatment outcome (Table 6) among Amoxicillin and Cefpodoxime Proxetil group, it was found insignificant association. 


\section{Discussion}

This open label randomized controlled trial was designed to compare the effect of oral Amoxicillin and cefpodoxime proxetil in children with pneumonia. Among the total enrolled children majority were boys. Age and sex distribution of this study found similarity with a study conducted by Jones $^{13}$. The baseline clinical features before therapy were not significantly different in both the amoxicillin and cefpodoxime proxetil group. Changes in duration of cough, duration of difficult breathing, duration of fast breathing, mean heart rate, mean temperature and mean respiratory rate were observed. After treatment with the amoxicillin and cefpodoxime proxetil, significant improvement in mean body temperature, respiratory rate and added sound were observed which were almost similar in both groups $(\mathrm{p}<0.001)$. WHO assemble an international panel to review the literature on childhood pneumonia and to develop evidence based recommendations for the empirical treatment of non-severe pneumonia among children managed by first-level health providers. Treatment should target the bacterial causes most likely that lead to severe disease, including Streptococcus pneumoniae and Haemophilus influenzae and the best first-line agent is Amoxicillin, given thrice daily for 5 days ${ }^{14}$.

In an international experience among 7351 patients, cefpodoxime proxetil has proven efficacious and well tolerated, and therefore should be added to antibacterial armamentarium for use in communityacquired infections and in hospitals for follow-up treatment after initial parenteral therapy ${ }^{15}$. Based on these characteristics, cefpodoxime proxetil is a suitable option for the treatment of paediatric patients with various common bacterial infections ${ }^{16}$. While comparing the efficacy of both the drugs, there was no such study found to compare in this era. In this trial, the treatment outcome in both groups showed that patients treating with amoxicillin and cefpodoxime proxetil cured more than two thirds of the patients. There was no statistically significant difference between patients treated with amoxicillin and those treated with cefpodoxime proxetil.

\section{Conclusion}

The baseline clinical characteristics before therapy are nearly same in both the groups. After treatment with amoxicillin and cefpodoxime proxetil, significant improvement in both the groups are observed. The response to therapy in both the groups are almost similar and the difference is statistically insignificant. Cefpodoxime proxetil is not found to have a superior efficacy than amoxicillin. Amoxicillin can still be used for community based treatment of pneumonia as it is cheaper and not resistant to common bacteria. Furthermore it can be used in all health care level as it is supplied by the government. Further study with large sample size should be conducted to validate the efficacy.

\section{References}

1. Cause-specific mortality estimates from: World Health Organization, Worla Health Report 2005: Make Every Mother and Child Count, World Health Organization, Geneva, under-five mortality estimates from: UNICEF, The State of the World's Children 2006, New York, 2005.

2. World Health Organization, International Statistical Classification of Diseases and Related Health Problems, Tenth Revision, World Health Organization, Geneva, 2006.

3. World Health Organization, Technical basis for the WHO recommendation on the management of pneumonia in children at first-level facilities. WHO/ARI/91.20. Geneva:WHO, 1991.

4. ISCAP Study Group. BMJ 2004;328:791.

5. Saha SK. Surveillance of peumococcus. Health \& Sciences Bull,2007.

6. Perez-Trallero E, Fernandez-Mazarrasa C, Garcia-Rey C, Bouza E, Aguilar L, Garcia-de-Lomas J et al. Antimicrobial susceptibilities of 1684 Streptococcus pneumoniae and 2039 Streptococcus pyogenes and their ecological relationships: results of a 1- year(1998-1999) multicenter surveillance in spain. Antimicrobial Agents and Chemotherapy 2001;45:3334-40.

7. Marchese A, Tonoli E, Debbia EA, Schito GC. Macrolide mechanisms and expression of phenotypes among Streptococcus pneumoniae circulating in Italy. Journal of Antimicrobial Chemotherapy 1999;44:461-4.

8. Kelly MA, Weber DJ, Gillian P, Cohen MS. Breakthrough pneumococcal bacteremia in patients being treated with azithromycin and clarithromycin. Clinical Infectious Diseases 2000:31:1008-11.

9. Fogarty C, Goldschmidt R, Bush K. Bacteremic pneumonia due to multidrug-resistant pneumococci in 3 patients treated unsuccessfully with levofloxacin. Clinical Infectious Diseases 2000:31:613-5.

10. Carbon C, Poole MD. The role of newer macrolides in the treatment of community-acquired respiratory tract infection. A review of experimental and clinical data. Journal of Chemotherapy 1999;11:107-18.

11. Geddes AM. Cefpodoxime proxetil in the treatment of lower respiratory tract infections. Drugs 1991;42:Suppl.3:34-40.

12. Gian CS, Apostolos G, Jose P. Antibacterial activity of oral antibiotics against community acquired respiratory pathogens from three European countries. Journal of Antimicrobial Chemotherapy 2002;50:Topic T1:7-11.

13. Jones G. How many child deaths can we prevent this year? The Lancet 2003;362:65-71.

14. Grant GB, Campbell H, Dowell SF, Graham SM, Klugman KP, Mulholland EK. Recommendations for treatment of childhood non severe pneumonia. Lancet 2009;9(3):185-96.

15. Klein M. Multicenter trial of cefpodoxime proxetil vs. Amoxicillin-clavulanate in acute lower respiratory tract infections in childhood. International Study Group. Pediatr Infect Dis J 1995;14(4 Suppl):S19-22.

16. Futon B, Perry CM. Cefpodoxime proxetil: A review of its use in the management of bacterial infections in pediatric patients. Pediatric Drugs 2001; 3(2): 137-158(22) 